\title{
Discussion of a Failure Hot-Spot Endurance Testing Case for CIGS Thin-Film Photovoltaic Module
}

\author{
Azen Y. Liu, S. L. Lai, Jimmy Yeh \\ Photovoltaic and Lighting Laboratory, Taiwan Electric Research and Testing Center, Taoyuan, Chinese Taipei \\ Email: azenliu@ms.tertec.org.tw, lai@ms.tertec.org.tw,jim@ms.tertec.org.tw
}

Received January, 2013

\begin{abstract}
This paper describes the use of steady-state solar simulator for CIGS thin-film photovoltaic module hot-spot endurance test. In the study, not only are test procedures of hot-spot endurance test in IEC 61646 discussed, but also how to evaluate the performance of steady-state solar simulator by IEC 60904-9 is presented. Three CIGS thin-film PV modules with the same types are used for hot-spot endurance test in case study. It is found that some of the cell damages and visual defects on tested PV modules are clearly observed.
\end{abstract}

Keywords: Hot-spot; Solar Simulator; CIGS; PV Module

\section{Introduction}

Photovoltaic (PV) module is mainly constructed by the series/parallel solar cell combinations. In normal light irradiation, when a serial branch of solar cell is shaded, the shaded solar cell may considered to be an open circuit which may required to withstand a large amount of reverse bias that is sum of remaining solar cells. For a long time use, such shaded solar cell may need to consume a high thermal energy, which may thus cause the cell damage to the shaded solar cell. The phenomenon is so-called PV module "hot-spot" effect. When design a PV module, bypass diodes are often used to prevent hot-spot effect. Otherwise to increase the strength of the material used in PV module is also a way to eliminate the thermal destruction caused by hot-spot effect. However, the discussions of hot-spot endurance problems in CIGS PV module are not often seen in past efforts [1]. This paper will therefore present a study of using steady-state solar simulator for CIGS PV modules hot-spot endurance test. Some of the failure tests will be discussed in case studies.

\section{Standard of Hot-Spot Endurance Test}

Hot-spot endurance test for thin-film PV modules is specified in section 10.9 of IEC 61646 standard [2]. Different cell constructions of PV modules (series, parallel or series-parallel-series) may provide with different hotspot endurance test procedures. This paper will focus on the discussion of PV modules with series combination cells. The relevant test procedures are summarized as below:

\subsection{To Find the Worst-case Shading Condition}

To set the irradiance of solar simulator to 800 to 1000 $\mathrm{W} / \mathrm{m}^{2}$ and to expose the PV module on this irradiance until thermal stabilization is reached. Measure the I-V characteristic of unshaded module, and obtain the maximum power current (Imp) and maximum power (Pmax1). The black heat-resistant tape (BT) that is cut into a small piece (similarly width and length of one cell) is used to cover the PV module; meanwhile, short-circuit current (Isc) is measured. Move the BT cover parallel to the cells and gradually increase the shaded module area number of shaded cells) until the Isc falls within the range of Imp, as shown in Figure 1, the worst-case shading condition is thus found.

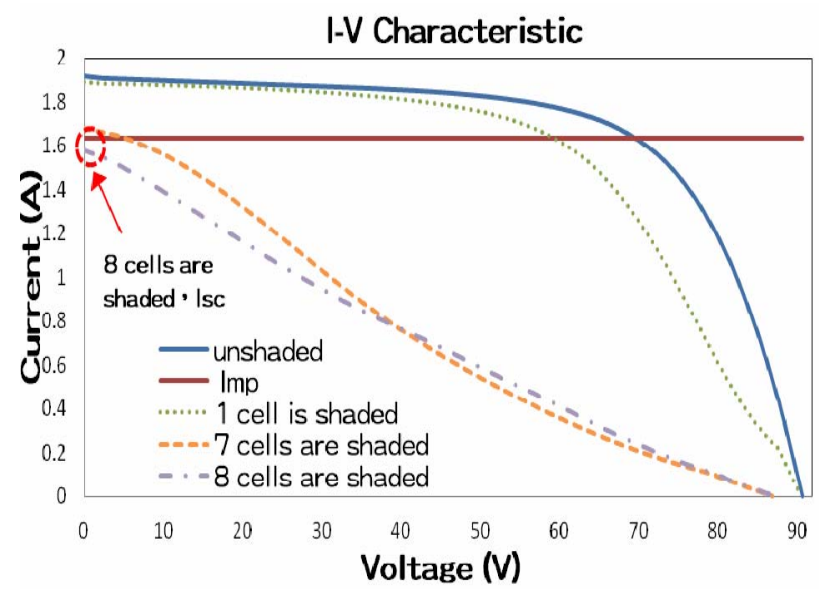

Figure 1. An example of worst-case shading condition of thin-film PV module with series combination cells. 


\subsection{To Decide the Worst-case Shading Position}

Cut the BT into the same size which is found on the worst-case shading condition. Slowly moves this BT cover from the bottom to the top of PV module (one cell distance of each movement) and monitor the $I_{\mathrm{sc}}$ of PV module. To find the module position that possesses the minimum $\mathrm{I}_{\mathrm{sc}}$ among the PV entire module, as shown in Figure 2. Then reduce/add the size of BT cover in small increments until $\mathrm{I}_{\mathrm{sc}}$ falls within the range of $0.99 \mathrm{I}_{\mathrm{mp}}<\mathrm{I}_{\mathrm{sc}}$ $<\mathrm{I}_{\mathrm{mp}}$. The final width and position of BT cover determines the minimum shading area that results in the worst-case shading condition. This is thus the shaded area to be used for hot-spot endurance test.

\subsection{Other Test Procedure and Test Duration}

Place the BT cover on the candidate PV module area and short-circuit the PV module. Again, expose the PV module to an irradiance to 800 to $1000 \mathrm{~W} / \mathrm{m}^{2}$ for 1 hour and control the temperature of $\mathrm{PV}$ module to $50^{\circ} \mathrm{C} \pm 10^{\circ} \mathrm{C}$. Meanwhile, monitor the value of $\mathrm{I}_{\mathrm{sc}}$ and keep the PV module in the condition of maximum power dissipation. An appropriate temperature detector is necessary used to determine the hottest area on the shaded cells. Finally, the visual inspection and insulation test are then used to judge if the PV module pass/fail in hot-spot endurance test.

\section{Steady-State Solar Simulator}

Solar simulator, which simulates the real solar irradiance and spectrum, is often used to provide a controllable indoor test field under laboratory condition and can be either used for performance measurements of PV cells/ modules or endurance irradiance tests. In general, solar simulator can be divided into three categories: steadystate, flash and pulse. The steady-state solar simulator, possessing a light source form where illumination is continuous in time, is most often used for low intensity testing from less than 1 sun up to several suns. The flash solar simulator, with typical durations of several milliseconds, includes very high intensities possibly up to several thousand suns. This type of simulator is often used to prevent unnecessary heat built up in the device under test (DUT). The pulse solar simulator, with typical durations of a few tens milliseconds to several hundred milliseconds, uses a shutter to quickly control the illumination of the light from a continuous source. The advantage of the pulse type simulator consists in the negligible heat influence to the DUT, which allows DUT to remain uniformity at ambient temperature and the measuring to be easily and accurately done [3]. In Figure 3, some experiments are implemented by steady-state solar simulator (SSSS) in case study, the used SSSS is consisted of 9 xenon lamps, xenon lamp power supply units, 4-wire I-V measuring system, reference cell, thermometer, module mounting plane, etc.

As shown in Table 1, current standard IEC 60904-9 describes three aspects, spectral match, non-uniformity irradiance and temporal instability of irradiance, to evaluate the performance requirement of solar simulator [4]. In general, a solar simulator with class B or better is required for PV cells/ modules performance testing. Following is the evaluation of SSSS used in the study:

\subsection{Spectral Match}

The spectral match is presented as the worst difference between the measured simulator spectral irradiance and referenced AM 1.5 G spectral irradiance as presented in IEC 60904-3, respectively, which cover six specified wavelength intervals between $400 \mathrm{~nm}$ and $1100 \mathrm{~nm}$ [5]. Figure 4 shows the measured SSSS spectral irradiance by high-speed spectroradiometer, and the deviations from AM 1.5 G are calculated in Table 2. It is found the spectral match to all wavelength intervals is among 0.930 to 1.068 , which is classified as A by using SSSS.

\subsection{Non-Uniformity of Irradiance}

The irradiance non-uniformity on the test plane of a large-area solar simulator for PV cells/modules measurements depends on reflection condition inside the test apparatus. Base on IEC 60904-9 the designated test area is divided into at least 64 equally sized test blocks, and then taken turn to detect the irradiance on each block. In the study, the test plane is divided into 100 equally sized test blocks. In Figure 5, the $\mathrm{I}_{\mathrm{sc}}$ of reference cell is recorded to present the irradiance distribution measured on this test plane. The maximum $\mathrm{I}_{\mathrm{sc}}$ in test plane is 128.2 $\mathrm{mA}$ and the minimum is $124.3 \mathrm{~mA}$. By substitute maximum and minimum $\mathrm{I}_{\mathrm{sc}}$ in (1), the non-uniformity of irradiance of $1.54 \%$ for used SSSS (classification $=\mathrm{A}$ ) is derived.

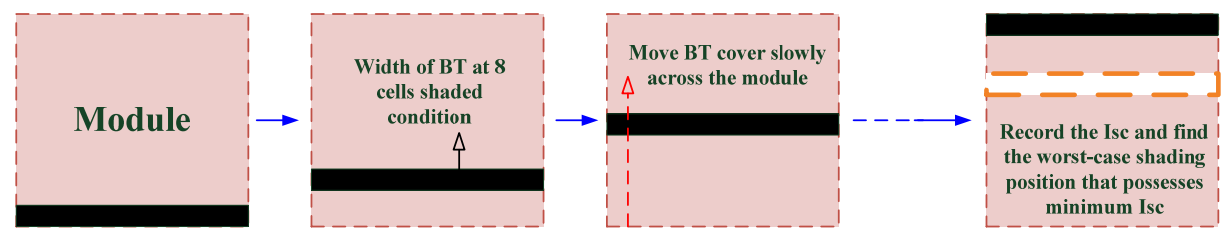

Figure 2. The procedure of searching worst-case shading position. 


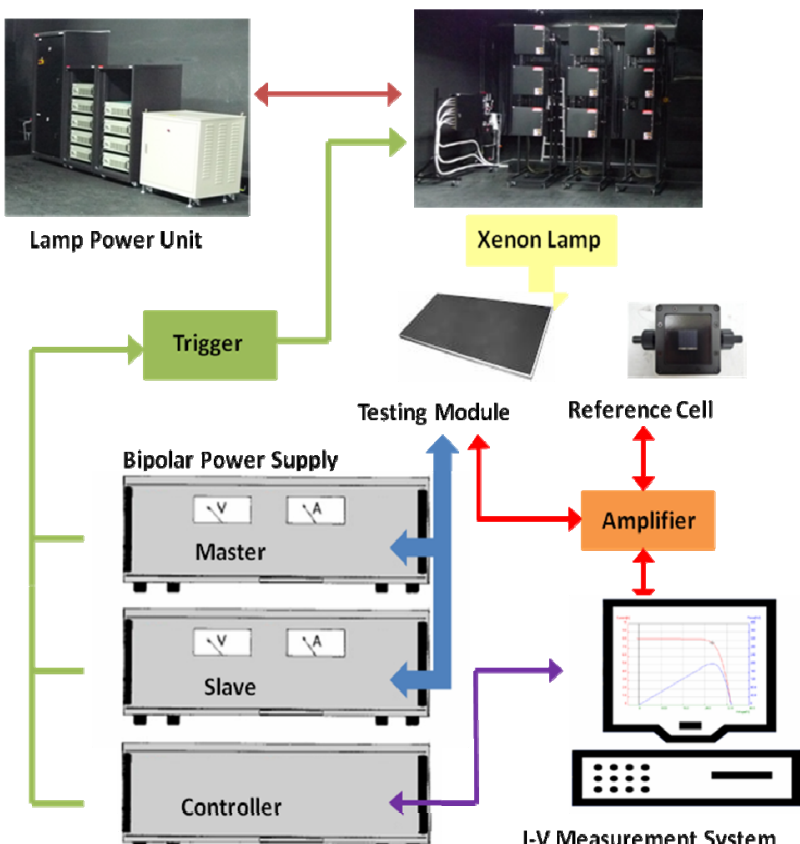

Figure 3. Steady-state solar simulator testing system.

Table 1. Definition of solar simulator classifications.

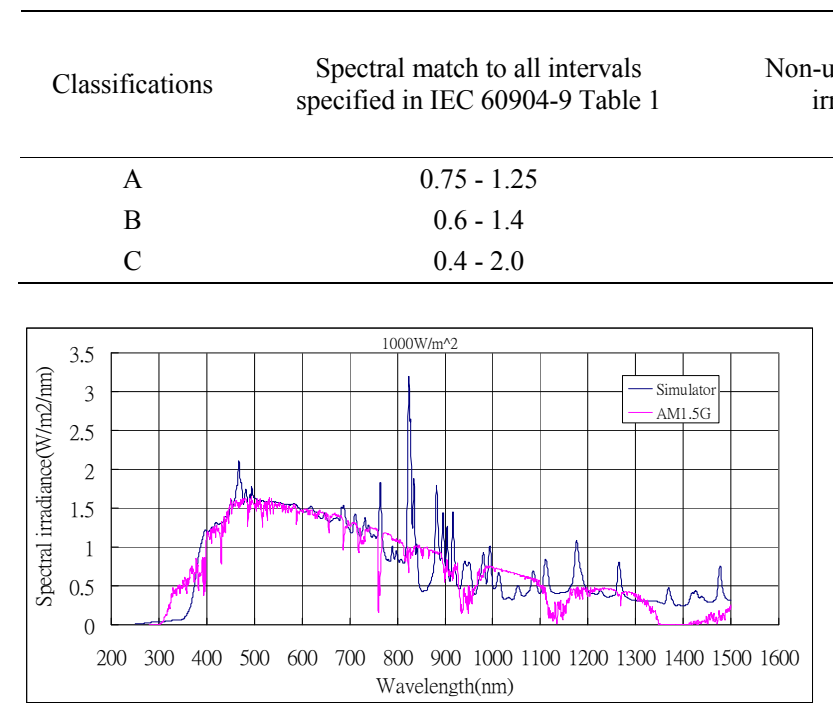

Figure 4. Measured spectral irradiance of SSSS.
Table 2. Spectral irradiance of lpss and Am 1.5g.

\begin{tabular}{cccc}
\hline $\begin{array}{c}\text { Wavelength range } \\
(\mathrm{nm})\end{array}$ & $\begin{array}{c}\text { Simulator Irradiance } \\
(1)\end{array}$ & AM 1.5G (2) & $(1) /(2)$ \\
\hline $400-500$ & 20.20 & 18.4 & 1.068 \\
$500-600$ & 20.80 & 19.9 & 1.008 \\
$600-700$ & 18.32 & 18.4 & 0.965 \\
$700-800$ & 14.50 & 14.9 & 0.966 \\
$800-900$ & 12.43 & 12.5 & 1.066 \\
$900-1100$ & 13.77 & 15.9 & 0.930 \\
\hline
\end{tabular}

\begin{tabular}{||r|r|r|r|r|r|r|r|r|r|r||}
\hline & No.1 & NO.2 & NO.3 & NO.4 & NO.5 & NO.6 & NO.7 & NO.8 & NO.9 & NO.10 \\
\hline NO.1 & 126.2 & 126.3 & 125.3 & 125.7 & 125 & 125.1 & 124.4 & 127.6 & 127.3 & 127.8 \\
\hline NO.2 & 126.5 & 127 & 127.4 & 126.2 & 125.7 & 125.9 & 125.4 & 127.7 & 127.9 & 126.3 \\
\hline NO.3 & 126.9 & 126.6 & 126.9 & 125.9 & 125.6 & 126.1 & 124.8 & 126.9 & 127 & 125 \\
\hline NO.4 & 126 & 125.7 & 126.8 & 126.1 & 126.3 & 126.6 & 124.8 & 126.5 & 126.9 & 124.3 \\
\hline NO.5 & 124.9 & 126.4 & 126.6 & 126.1 & 127 & 127 & 124.6 & 126.7 & 126.9 & 124.6 \\
\hline NO.6 & 124.7 & 126.7 & 127.2 & 126.9 & 127.1 & 128.1 & 125.8 & 127.6 & 127.6 & 125.1 \\
\hline NO.7 & 124.8 & 126.8 & 127.1 & 126.6 & 126.9 & 127.6 & 125.2 & 127.5 & 127.7 & 125.6 \\
\hline NO.8 & 125.5 & 127.3 & 127.5 & 126.8 & 126.6 & 127.5 & 125.6 & 127.8 & 127.6 & 126.1 \\
\hline NO.9 & 126.3 & 127.9 & 128.2 & 127.2 & 126.4 & 127.6 & 126.3 & 128.2 & 128.2 & 126.8 \\
\hline NO.10 & 125.8 & 127.6 & 127.6 & 126.4 & 125.4 & 126.8 & 125.1 & 127.7 & 127.5 & 125.5 \\
\hline \hline
\end{tabular}

Figure 5. Measured irradiance distribution in the test plane (current, A). 


$$
\begin{aligned}
& \text { Non-uniformity }(\%) \\
= & {\left[\frac{\text { max irradiance }- \text { min irradiance }}{\text { max irradiance }+ \text { min irradiance }}\right] \times 100 \% }
\end{aligned}
$$

\subsection{Temporal of Instability of Irradiance}

Temporal Instability is the third performance parameter for SSSS evaluation. It requires the output light to be stable over time in order to ensure that the lamp fluctuations do not affect the measurement of solar cell efficiency. In general, both short-term instability (STI) and long-term instability (LTI) should be evaluated. For SSSS evaluation where the data acquisition system is integrated into the simulator itself which can simultaneously store three separate data (irradiance, voltage and current), the temporal instability is thus classified as A for STI. Figure 6 shows instability responses for SSSS, a sample rate of 6 second and elapsed time 2 hours is utilized to calculate LTI. It is found the maximum irradiance of $1000.82 \mathrm{~W} / \mathrm{m}^{2}$ and the minimum irradiance of 998.89 $\mathrm{W} / \mathrm{m}^{2}$ is measured within these time durations. LTI of $0.096 \%$ is thus calculated that less than a maximum allowable level of $0.5 \%$ classified as $\mathrm{A}$ is obtained.

\section{Case Study}

Three CIGS thin-film PV modules with the same specification are used for hot-spot endurance test in this paper. Following is the discussion about the trial phenomena observed on hot-spot endurance test which is performed on laboratory test environment.

$>$ After one hour exposure of hot-spot endurance test, the corrosion caused on the cell surface of sample 1 module. is obviously found, as show in Figures 7 and 8. However based on the IEC 61646 standard the cell damage caused by reverse bias in the hot-spot endurance test was not considered a void or corrosion of the thin-film layers. Which means if there is no problem in following visual inspection and insulation test, sample 1 module is still considered to pass the hot-spot endurance test. The value of measured insulation resistance for sample 1 is $211 \mathrm{M} \Omega$ which is not less than the limitation.

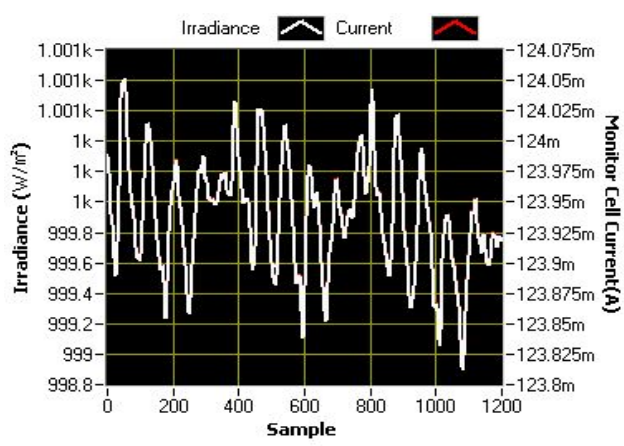

Figure 6. Output light variation of used SSSS.

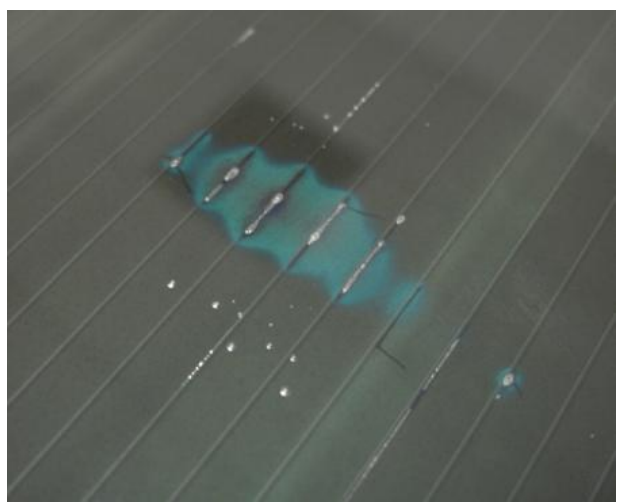

Figure 7. Corrosion effect caused on sample 1 module (near central cell of module).

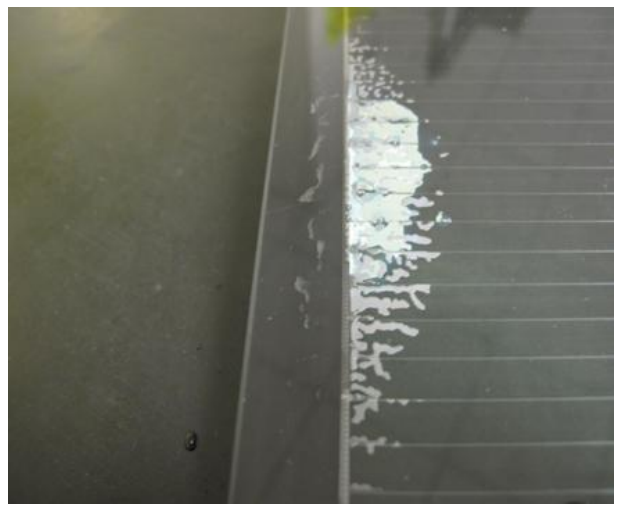

Figure 8. Corrosion effect caused on sample 1 module (near module frame.

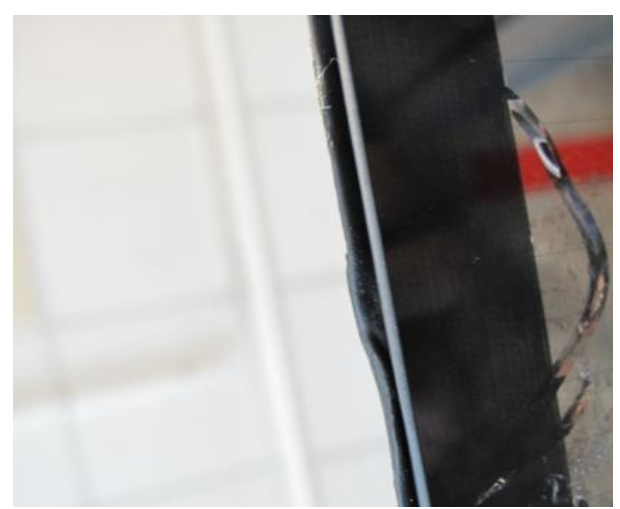

Figure 9. Broken rear side cover glass of sample 2 module.

It is found that the corrosion phenomenon that occurred on the cells (which is shaded with BT cover) of sample 2 module after one hour exposure as well, as shown in Figure 9. The thermal image, which is captured by IR camera, of sample 2 module can be shown in Figure 10. A significant heat is concentrated in the position where BT is covered on sample 2 module. The position is near with module frame and junction box. For a long time exposure, the cover glass on the rear side of sample 2 module is broken. 


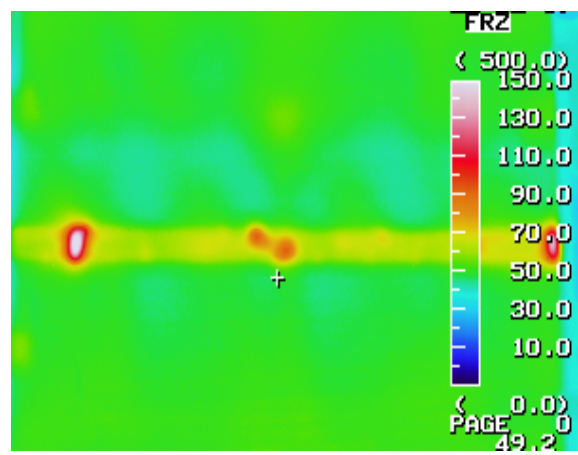

Figure 10. Thermal image captured form sample 2 module.

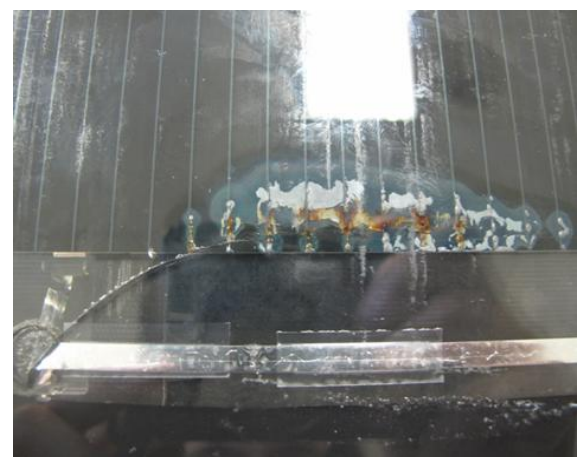

Figure 11. Broken rear side cover glass of sample 3 module.

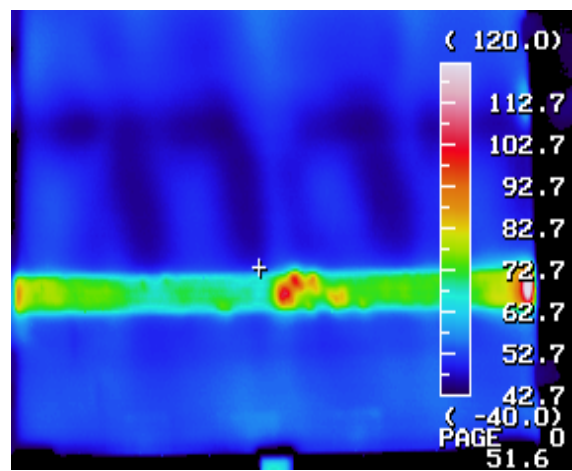

Figure 12. Thermal image captured form sample 3 module.
The similar results are presented on sample 3 module, but the broken cover glass on the rear side of this sample is found close to junction box, as shown in Figures 11 and 12. Sample 2 and 3 module cause the insulation failure due to the broken of module cover glass. The measured insulation resistance of sample 2 and 3 are $11.45 \mathrm{M} \Omega$ and $8.62 \mathrm{M} \Omega$, respectively, which are less than the limitation of such module type.

\section{Conclusions}

Carry out of hot-spot endurance test for thin-film PV module by steady-state solar simulator is presented in this paper. The performance evaluation of used steadystate solar simulator based on the procedures described in IEC 60904-9 standard is presented as well. Three CIGS thin-film PV modules are used in case study for the discussion of PV modules face hot-spot effect. It is found the destruction of cover glass is the most common seen problem in testing samples. The insufficient stress strength of rear side cover glass of testing modules is considered as the main reason in this study.

\section{REFERENCES}

[1] A. J. Breeze, "Next Generation Thin-film Solar Cells," IEEE Conference on Reliability Physics Symposium (IRPS), 2008, pp. 168-171.

[2] IEC 61646, "Thin-film Terrestrial Photovoltaic (PV) Modules - Design Qualification and Type Approval," 2008.

[3] M. Shimotomai, Y. Shinohara and S. Igari, "The Development of the I-V Measurement by Pulsed Multi-flash, and the Effectiveness," IEEE Conference Photovoltaic Energy Conversion (WCPEC), Vol. 2, 2006, pp. 2223-2226.

[4] IEC 60904-9, "Photovoltaic Devices - Part 9: Solar simulator Performance Requirements," 2007.

[5] IEC 60904-3, "Photovoltaic Devices - Part 3: Measurement Principles for Terrestrial Photovoltaic (PV) Solar Devices with Reference Spectral Irradiance Data,” 2008. 